\title{
O QUE É A DESCONSTRUÇÃO?
}

\author{
What' s deconstruction?
}

José Antonio Vasconcelos ${ }^{1}$

\section{Resumo}

Este artigo busca delinear uma compreensão da desconstrução como estratégia articulada à filosofia de Jacques Derrida. Nesse sentido, cumpre destacar alguns exemplos de como a atividade desconstrucionista trabalha, em especial a desconstrução que Derrida faz da argumentação de Lévi-Strauss em torno dos mitos. Por fim, cumpre também esclareceralguns equívo cos em tomo da desconstrução, que muitas vezes é utilizada como conceito ou método de análise, domesticando assim completamente seu potencial de abalar as estruturas do pensamento logocêntrico.

Palavras-chave: Desconstrução; Pós-estruturalismo; Derrida.

\section{Abstract}

This article aims to outline an understanding of deconstruction as a strategy articulated to the philosophy of Jacques Derrida. In this task, it is important to discuss some examples of how deconstruction works, and especially the deconstruction Derrida operates on Levi-Strauss' arguments on myths. In the end it is also important to clarify some misunderstandings about deconstruction, which is frequently used as a concept or method of analysis, for this domesticates its potential of undermining the structures of logocentric thought. Keywords: Deconstruction; Post structuralism; Derrida.

1 Doutor em História pela Unicamp e professor da Universidade Tuiuti do Paraná

E mail :. historicismo@hotmail.com 


\section{Introdução}

O pós-estruturalismo tem freqüentemente sido colocado como instância crítica frente às pretensões de objetividade nas pesquisas em ciências humanas. Na verdade, quanto mais nos aprofundamos na literatura sobre o pós-estruturalismo, mais podemos perceber o quanto este se apresenta como um fenômeno complexo e confuso. Em primeiro lugar, o próprio prefixo "pós" pressupõe uma compreensão do estruturalismo que o precedeu, e que, devemos admitir, é bastante problemática. Basta dizer que o termo "estruturalista" tem sido muitas vezes usado com referência a autores de áreas e perspectivas diversas e, por vezes, irreconciliáveis. Uma lista de autores estruturalistas incluindo os nomes de Ferdinand de Saussure, Claude Lévi-Strauss, Femand Braudel, Wladmir Propp e Michel Foucault, por exemplo, já seria o suficiente para dar uma noção do que quero dizer. Em segundo lugar, mesmo que tenhamos definido, grosso modo, o que entendemos por estruturalismo, nos caberia formular uma definição de "pós-estruturalismo" que fosse tão simples e direta quanto possível, de modo que pudesse servir de princípio para um estudo mais aprofundado, e, ao mesmo tempo, tão abrangente quanto possível, de modo a abarcar todos os autores e escritos classificados sob esta rubrica. Por fim, para complicar ainda mais este cenário, tal lista de autores e obras pósestruturalistas simplesmente não existe. Jacques Lacan, Louis Althusser e Michel Foucault, por exemplo, figuram em alguns comentadores como estruturalistas e em outros como pós-estruturalistas, sem que haja consenso definitivo a esse respeito. O mesmo pode ser dito de Roland Barthes, pois muitos de seus livros e ensaios apresentam aspectos pós-estruturalistas sobre um pano de fundo estruturalista bastante tradicional. $\mathrm{O}$ estudo de uma tendência tão vaga e difusa, portanto, soaria desanimador não fosse pela impressionante repercussão dos escritos de Jacques Demida, um autor inequivocamente associado ao pósestruturalismo, e cujas idéias nos servirão de roteiro para a compreensão desta corrente teórica.

O pós-estruturalismo utiliza a teonia estruturalista para questionar e tomar problemáticas - mas não negar - as premissas do próprio estruturalismo. Nesse sentido, o pós-estruturalismo, em relação a seu predecessor, poderia ser metaforicamente comparado a alguém que avança numa piscina cada vez mais funda até que seus pés não mais possam tocar o chão. Quando o estruturalismo "perde o chão", penetramos no domínio pós-estruturalista. Embora essa imagem, em virtude de sua própria simplicida- de, obviamente não possa esgotar um fenômeno tão rico e, ao mesmo tempo, tão indefinido quanto o pensamento pós-estruturalista, ela é útil para ilustrar o efeito produzido pela desconstrução, uma estratégia para a leitura de textos desenvolvida por Derrida, a qual, ainda que inadequadamente, tem sido freqüentemente associada ao empreendimento pós-estruturalista como um todo.

\section{Desconstrução: um conceito?}

Por mais tentador que isso pareça ser, a desconstrução não pode, de acordo com Derrida, ser entendida como um conceito ou como um método, sob pena de absolutamente não entendermos a novidade do pensamento desconstrucionista, que tenta subverter as próprias noções de conceito e método. Eis porque Derrida (1975, P.5354), em certas passagens, ao escrever sobre a desconstrução, prefere utilizar o termo "estratégia":

$\mathrm{O}$ que me interessava naquele momento [da escrita de La dissemination, La double séance e La mythologie blanchel, o que tento continuar agora sob outras vias, é, a par de uma "economia geral", uma espécie de estratégia geral da desconstrução. [...] É, pois necessánio antecipar um duplo gesto, segundo uma unidade simultaneamente sistemática e como que afastada de si mesma, uma escrita desdobrada, isto é multiplicada por si própria, aquilo a que chamei em "La double séance, uma dupla ciência: por um lado, atravessar uma fase de derrubamento. [...] aceitar essa necessidade é reconhecer que, numa oposição filosófica clássica, não tratamos com uma coexistência pacífica de um vis-a-vis, mas com uma hierarquia violenta. Um dos dois termos domina o outro (axiologicamente, logicamente, etc.), ocupa o cimo. Desconstruir a oposição é primeiro, num determinado momento, derrubar a hierarquia.

Para Derrida, o pensamento metafísico tradicional, por ele chamado de logocêntrico, jamais se desvinculou de uma abordagem que identifica pares de oposições - razão e sensação, espírito e matéria, identidade e diferença, lógica e retórica, masculino e feminino etc., mas, sobretudo, fala e escrita -, estabelecendo a primazia do primeiro sobre o segundo termo da oposição. Esta hierarquização das relações opositivas nos remete a uma categoria fundamental, a presença, a partir da qual podemos explicar a realidade em geral. Segundo Derrida: 
A história da metafísica, como a história do Ocidente, seria a história dessas metáforas e dessas metonímias [os diferentes nomes que utilizamos para nos referir a um centro ou fundamento estável a partir do qual possamos pensar a totalidade de uma estrutura ou mesmo da realidade em geral]. A sua forma matricial seria espero que me perdoem por ser tão pouco demonstrativo e tão elítico, mas é para chegar mais depressa ao meu tema principal - a determinação do ser como presença em todos os sentidos desta palavra. Poder-se-ia mostrar que todos os nomes do fundamento, do princípio, ou do centro, sempre designaram o invariante de uma presença (eidos, arquê, telos, energeia, ousia (essência, existência, substância, sujeito) alehteia, transcendentalidade, consciência, Deus, homem, etc.) (1995, p. 231).

Num primeiro momento, a desconstrução visa a inverter a hierarquia dos conceitos, procurando pensar o segundo termo como principal e originário. Na relação entre causa e efeito, por exemplo, este é tradicionalmente entendido como secundário e derivado daquela. Mas, em nossa experiência, primeiramente constatamos a manifestação do efeito, para então remontarmos a suas causas. Assim concebido, o efeito é que deveria ser tido como originário, pois é por causa dele que um fenômeno pode ser concebido como causa. Em outras palavras, numa perspectiva desconstrucionista, o efeito é entendido como a causa de sua própria causa. ${ }^{2}$ Outro exemplo: a condição masculina só é concebível em sua relação àquilo que ela não é. A idéia de homem só pode ser pensada enquanto tal na medida em que estiver em oposição às idéias de mulher ou gay. $O$ Outro, portanto, é essencial à compreensão de $\mathrm{Si}$ Mesmo, e, em função disso, não pode ser considerado como algo meramente acidental e secundário.

Pensar o termo inferior como principal, produzir o derrubamento da hierarquia, como sugere Derrida, constitui, deste modo, o primeiro passo na dinâmica de uma abordagem desconstrucionista. Contudo, permanecendo simplesmente neste momento de inversão, continuaremos ainda presos a uma perspectiva logocêntrica. Uma oposição hierárquica, mesmo sendo invertida, continua sendo hierárquica. Nesse sentido, e isto o próprio Derrida o reconhece, esta fase de derrubamento seria análoga à clássica oposição entre tese e antítese proposta pela lógica hegeliana. Em Posições, Derrida afirma: . "A diferância [tradução portuguesa de différance, um conceito derridiano nesse texto associado à desconstrução] deve assinar (num ponto de proximidade quase absoluta com Hegel [...]), o ponto de ruptura com a Aufhebung e da dialética especulativa" (DERRIDA, 1975, p. 56). A prática da desconstrução, portanto, consiste em inverter a hierarquia tradicionalmente estabelecida entre um conceito e seu oposto correlato, para em seguida estabelecer, não a redução de um conceito a outro, como postularia a filosofia de Hegel, mas sim o jogo, a incessante alternância de primazia de um termo sobre o outro, produzindo, assim, uma situação de constante indecisão. Vejamos como Derrida apresenta essa passagem do derrubamento ao jogo, contrastando sua abordagem com a de Hegel:

A partir daí, para marcar este desvio [isto é, a prática da desconstrução seguindo o momento de inversão das hierarquias] [...] foi preciso analisar, fazer trabalhar algumas marcas, tanto no texto da história da filosofia como no texto "literário" [...], marcas essas [...] a que chamei por analogia (sublinho-o) indefiníveis, isto é, unidades de simulacro, "falsas" propriedades verbais, nominais ou semânticas, que já não se deixam compreender na oposição filosófica (binária) e que, todavia a habitam, lhe resistem, a desorganizam, mas sem nunca constituírem um terceiro termo, sem nunca darem uma solução na forma dialéctica especulativa [...]. De facto, é contra a reapropriação incessante desse trabalho de simulacro numa dialéctica de tipo hegeliano (que chega a idealizar e a "semantizar" este valor de trabalho) que me esforço por levar a operação crítica, já que o idealismo hegeliano consiste justamente em superar as oposições binánias do idealismo clássico, em resolver sua contradição num terceiro termo que vem "aufheben", negar superando, idealizando, sublimando numa interioridade anamnésica (Errrinerung), internando a diferença numa presença-a-si (1975, pp. 55-56).

O termo "jogo", empregado por Derida com relação a esta segunda fase da desconstrução, foi proposto a princípio numa palestra - "Estrutura, signo e jogo no discurso das ciências humanas" -, apresentada na Universidade de Johns Hopkins, em 1966, e posteriormente publicada numa coletânea intitulada A escritura ea diferença. Na verdade, nesse texto Derrida somente se refere ao jogo de maneira indireta, sem explicar em qualquer momento 0 que é o jogo, em que este consiste. E isso em função de um princípio fundamental da filosofia demidiana: o de que não existe princípio, fundamento ou conceito que seja anterior ou esteja fora do jogo de diferenças que operam em qualquer discurso. Deste 
modo, afirmar que "o jogo é isto" ou "o jogo é aquilo" seria reduzir essa noção ao sistema de oposições que ela visa subverter. "O jogo", de acordo com Derrida, "é sempre um jogo de ausência e presença, mas se o quisermos pensar radicalmente, é preciso pensá-lo antes da alternativa da presença e da ausência; é preciso pensar o ser como presença ou ausência a partir da possibilidade do jogo, e não inversamente" (DERRIDA, 1971, p. 248).

\section{A Desconstrução em ação}

Uma das principais características da abordagem desconstrucionista, tal como praticada por Derrida, é a apropriação e utilização de conceitos derivados de um sistema de pensamento para, ao final, mostrar como esse sistema não funciona. Voltando ao exemplo a que me referi anteriormente, se afirmarmos que o efeito é a causa que faz com que a causa possa ser concebida enquanto tal, nós estaremos lançando mão de um conceito - o de causa para questionar o próprio sistema - o da causalidade - no qual este conceito se fundamenta. De acordo com Jonathan Culler (1994), teórico do estruturalismo e pós-estruturalismo literánios, "este duplo procedimento de sistematicamente empregar os conceitos ou premissas que se está solapando, coloca 0 crítico numa posição, não de distanciamento cético, mas de um envolvimento sem garantias, afirmando que a causalidade é indispensável ao mesmo tempo em que se nega a esta qualquer justificação rigorosa". E acrescenta: "este é um aspecto da desconstrução que muitos acham difícil de entender e aceitar" (p.87-88).

Para que possamos perceber melhor essa característica da abordagem desconstrucionista, vamos tomar como exemplo o texto "Estrutura, signo e jogo no discurso das ciências humanas". Nele, Dernida parte de uma oposição binária entre o dentro e 0 fora do centro numa estrutura. De acordo com Derrida, "a estrutura, ou melhor, a estruturalidade da estrutura, embora tenha sempre estado em ação, sempre se viu neutralizada, reduzida: por um gesto que consistia em dar-lhe um centro, em relacioná-la a um ponto de presença, a uma origem fixa" (1971, p.230). Esse centro seria então uma condição necessária para a substituição dos elementos no interior de uma estrutura, mas, ao mesmo tempo, um elemento dessa estrutura que não se presta à substituição. Nesse sentido, podemos dizer que, paradoxalmente, o centro está, ao mesmo tempo, dentro da estrutura e fora dela. Isso permite a Derrida afirmar que o "conceito de estrutura centrada - embora represente a própria coerência, a condição da episteme como filosofia ou como ciência - é contraditoriamente coerente".(Ibidem, p. 230). Na prática da descontrução, portanto, não se trata de reduzir o exterior ao interior, nem de celebrar anarquicamente o predomínio do conceito de fora sobre o de dentro, mas, a partir dessa oposição, procurar pensar o jogo que a antecede e a toma possível.

Esta primeira oposição, na verdade, constitui um preâmbulo, a partir do qual Derrida dá início a uma discussão sobre o empreendimento estruturalista, e, em particular, aquela versão de estruturalismo representada pela obra de Claude Lévi-Strauss. Também nas teorias desse autor, Derrida identifica pares de conceitos opostos que são submetidos à crítica desconstrucionista: etnocentrismo e descentramento, pensamento conceitual e pensamento mítico, engenheiro e bricoleur, e, relacionados a estes, ainda os conceitos de significante e significado, e de sensível e inteligível.

Para ilustrar a estratégia desconstrucionista utilizada por Derrida, tomemos a oposição entre conceito e mito e observemos como ela se torna problemática na obra de Lévi-Strauss. Este, de acordo com Derrida, reconhece que "o discurso sobre esta estrutura a-cêntrica que é o mito não pode ele próprio ter sujeito e centro absolutos. Deve, para apreender a forma e o movimento do mito, evitar a violência que consistinia em centrar uma linguagem descritiva de uma estrutura a-cêntrica". Desse modo, somos levados à conclusão de que "Por oposição ao discurso epistêmico, o discurso estrutural sobre os mitos, o discurso mito-lógico deve ser ele próprio mitomorfo".(Ibidem, p. 241) Por isso é que, em Le cru et le Cuit, Lévi-Strauss chega a admitir que "será acertado considerá-lo [seu livro] como um mito: de qualquer modo, o mito da mitologia" (LÉVI-STRAUSS apud DERRIDA, p. 242).

Esta primeira fase de derrubamento, de inversão de uma hierarquia previamente estabelecida por uma perspectiva etnocêntrica, que afirmava a prioridade do pensamento conceitual sobre 0 pensamento mítico, do raciocínio lógico sobre a bricolagem, e que é levada a cabo pelo próprio Lévi-Strauss, nos força a pensar o mito como uma forma de pensamento oniginal, irredutível à lógica e até mesmo como condição da própria episteme. Mas a desconstrução derridiana vai além, questionando, em primeiro lugar, o alcance de uma abordagem que pretende ultrapassar os limites colocados pela metafísica tradicional, e que, ao mesmo tempo, utiliza uma linguagem denivada dessa mesma tradição. 
Não tem nenhum sentido abandonar os conceitos da metafísica para abalar a metafísica; não dispomos de nenhuma linguagem - de nenhuma sintaxe e de nenhum léxico - que seja estranho a essa história; não podemos enunciar nenhuma proposição destruidora que não se tenha já visto obrigada a escorregar para a forma, para a lógica e para as postulações implícitas daquilo mesmo que gostaria de contestar". (DERRIDA, 1971, p. 233).

Sendo assim, diante de um gesto que faria sucumbir a noção de conceito - e, deste modo, toda a Filosofia, tal como a entendemos, sob a primazia do mito, Derrida faz uma pausa, colocando o seguinte questionamento:

Contudo, se nos rendermos à necessidade do gesto de Lévi-Strauss, não podemos ignorar os seus riscos. Se a mito-lógica é mito-mórfica, será que todos os discursos sobre os mitos se equivalem? Dever-se-á abandonar toda exigência epistemológica permitindo distinguir entre várias qualidades do discurso sobre o mito?Questão clássica, mas inevitável. Não podemos responder a ela - e creio que Lévi-Strauss não lhe responde - enquanto não tiver sido expressamente exposto o problema das relações entre 0 filosofema ou o teorema de um lado, e o mitema ou mitopoema do outro (Ibidem, p. 242).

Ora, se há relação entre filosofema e mitema, e se sabemos que estes ocupam lugares opostos, é porque uma distinção pode e deve ser feita entre esses dois conceitos, para que, ao invés de reduzirmos um ao outro, possamos pensar o jogo existente entre ambos. Sem esta segunda fase, a desconstrução permaneceria incompleta. Ao que, Derrida acrescenta: "O que pretendo acentuar é apenas que a passagem para além da Filosofia não consiste em virar a página da Filosofia, (o que finalmente acaba sendo filosofar mal) mas em continuar a ler de uma certa maneira os filósofos" (Ibidem, p. 243).

Como podemos perceber, portanto, a desconstrução derridiana não tem por objetivo negar, simplesmente e levianamente, o valor da tradição filosófica ocidental, ou negar qualquer distinção entre conceito e mito, ou entre Filosofia e Literatura. O que Demida busca realizar, em todos os seus escritos, é um questionamento, uma crítica rigorosa dos limites de uma filosofia da representação, para que possamos vislumbrar a possibilidade de uma forma de pensamento que esteja além - ou aquém - desses limites. Mas o fato, é que Derrida tem sido freqüen- temente visto como um teórico niilista, dando aval à livre interpretação, destituída de qualquer rigor crítico. Christopher Norris, discutindo a desconstrução em Derrida, contrapõe-se com insistência a esse ponto de vista, argumentando que "tratar a desconstrução como um convite aberto a formas novas e mais aventurosas de crítica interpretativa é claramente equivocar-se com relação àquilo que é mais distintivo e exigente nos textos de Derrida" (NORRIS, 1987, p. 20). E ainda:

A ênfase de Derrida sobre a textualidade e a escrita não é, em qualquer sentido, uma ruptura com a filosofia, ou uma declaração de liberdades interpretativas até então não sonhadas sob a severa lei repressiva da clareza e verdade conceituais. Que esta impressão esteja tão divulgada é parcialmente o resultado de que os filósofos tenham mostrado pouca vontade em ler Derrida, mas um zelo incomum em denunciá-lo com base em conhecimento de segunda mão de seu trabalho.

[...] Como eu já argumentei - e argumentarei novamente -, a desconstrução é mal servida por aqueles fanáticos de uma "liberdade" textual ilimitada, que rejeitam as próprias noções de pensamento rigoroso ou de crítica conceitual (Ibidem, p. 21, 27).

Quando Norris usa os termos "filósofos" e "fanáticos", devemos entender, respectivamente, uma tendência majoritária nos estudos filosóficos norteamericanos, de orientação analítica, cuja recepção de Derrida se faz por intermédio dos departamentos de Literatura, ao lado de uma corrente da Teoria Literária americana que interpreta as idéias de Derrida, muitas vezes tendo apenas uma compreensão superficial da tradição metafísica que ele critica. Segundo Jonathan Culller, essa tendência da Teoria Literária constitui, de fato, um novo gênero nos estudos literários, o qual geralmente chamamos de "teoria". Mas, ao mesmo tempo, Culler observa que os "estudantes de teoria lêem Freud sem se perguntarem se a pesquisa posterior em Psicologia possa ter contradito suas formulações; eles lêem Derrida sem ter dominado a tradição filosófica; eles lêem Marx sem estudar descrições alternativas de situações políticas e econômicas" (CULER, 1994, p. 9). Não que, segundo Culler, isso seja necessariamente ruim. Pelo contrário, em seu entender a leitura de textos "canônicos" fora de sua matriz disciplinar pode contribuir para a produção de significados novos e inusitados. Contudo, permanece o fato de que a estratégia desconstrucionista, tal como é levada a 
efeito por Derrida, não pode ser tomada como equivalente à prática da desconstrução do modo como é realizada por seus seguidores no campo da Teonia Literánia.

\section{Desconstrução: usos e abusos}

Na verdade, o termo "desconstrução" é apenas um entre os inúmeros neologismos cunhados por Derrida, tais como fonocentrismo, logocentrismo ou différrance. E mais: em seus escritos, Derrida não confere a esse termo tanto destaque quanto é dado não só por muitos de seus admiradores, mas também, e talvez principalmente, pela maionia de seus opositores. Mas o fato é que a palavra "desconstrução" ganhou espaço e tornou-se um jargão corrente na Teoria Literária, em especial nos Estados Unidos. É interessante notar que a difusão das idéias de Derrida na América do Norte, dando-se a partir dos departamentos de Teoria Literária, mais do que dos próprios departamentos de Filosofia, é um fenômeno observado por vários comentadores.

Embora a desconstrução enquanto método, conceito ou categoria de análise tenha se tomado uma prática comente no estudo da literatura, principalmente nos Estados Unidos, e embora o próprio Derrida tenha admitido que seu interesse pela literatura precedeu e dirigiu suas preocupações filosóficas, devemos lembrar que sua filosofia desenvolveuse, sobretudo, enquanto crítica ao estruturalismo, e em especial ao modelo lingüístico - e não literánio proposto primeiramente por Ferdinand de Saussure. Devemos lembrar também que, apesar da imensa receptividade de suas idéias no meio acadêmico norteamericano, Derrida revela uma certa reserva quanto a certos aspectos do desconstrucionismo na América. Christopher Noris, ao abordar o tema da desconstrução, observa:

às vezes Derrida se exime de toda responsabilidade por tais leituras equivocadas [que interpretam a desconstrução como se esta fosse um 'método', uma 'técnica' ou uma espécie de crítica], tomando-as como um tipo de déformation professionelle, o resultado de se enxertar a desconstrução numa atividade com suas próprias necessidades e pré-requisitos" (NORRIS, 1987, p. 18).

Não pretendo, com essas considerações, fazer uma apologia do "verdadeiro" Demida ou de uma descontrução "autêntica", pois isto implicaria na busca de uma Presença que o próprio pós-estruturalismo coloca sob suspeita. Mas não podemos ignorar que, transformando a desconstrução num conceito ou num método de análise, acabamos domesticando seu potencial de abalar as estruturas do pensamento logocêntrico.

\section{Nota}

2 Embora o exemplo da relação causa/efeito aqui utilizado não tenha sido proposto propriamente por Derrida, mas sim por Nietzsche, ele é apresentado, acertadamente, acredito, por Jonathan Culler, como um exemplo de desconstrução característica da abordagem pós-estruturalista (CULLER, 1994, p. 86-88).

\section{Referências}

CULER, Jonathan. On deconstruction. Ithaca : Comell University Press, 1994.

DERRIDA, Jacques. Margens da Filosofia. Campinas : Papinus, 1991.

Posições: semiologia e materialismo. Lisboa : Plátano, s.d.

A escritura e a diferença. São Paulo : Perspectiva, 1971. ras, 1997.

A farmácia de Platão. São Paulo : Iluminu-

Gramatologia. São Paulo : Perspectiva, 1999.

Limited Inc. Campinas : Papirus, 1991.

Spurs: Nietzsche’s styles/Éperons: les styles de Nietzsche. Chicago : University of Chicago Press, 1996.

EAGLETON, Terry. Literary theory: an introduction. Minneapolis : University of Minnesota Press, 1983.

FREADMAN, Richard; MLLER, Seumas. Re-pensando a teoria: uma crítica da teoria literária contemporânea. São Paulo: Editora da Unesp, 1994.

LENTRICCIA, Frank. After the new criticism. Chicago : University of Chicago Press, 1980.

NORRIS, Christopher. Derrida. Cambridge : Harvard University Press, 1987.

RAGO, Margareth; GIMENEZ, Renato Aloizio de Oliveira. Narrar o passado, repensar a História. Campinas : IFCH, Unicamp, 2000.

Recebido em 23/10/2003

Aprovado em 21/11/2003 